\title{
FORMULATION AND EVALUATION OF CHRONOTHERAPEUTIC DRUG DELIVERY SYSTEM OF MELOXICAM
}

\author{
* Ratnaparkhi Mukesh P., Khade Ravindra B., Chaudhari Shilpa P. \\ Marathawada Mitra Mandals College of Pharmacy, University of Pune, Pune, India- 411033 \\ *Corresponding Author's Tel +919960865355, Email ID: mukeshparkhi@yahoo.co.in
}

\begin{abstract}
The objective of this work is to formulate a pulsatile drug delivery system using Meloxicam drug. The drug delivery system was designed to deliver the drug in such a way that it could be most useful to the patient of rheumatoid arthritis. A core in cup (three component tablet) is prepared where in core tablet, an impermeable material surrounding the tablet except the top and soluble hydrophilic polymer layer at the top is designed. The core tablet contains Meloxicam, ethyl cellulose is used as impermeable membrane and polyethylene oxide used as soluble hydrophilic polymer layer. The release profile of press coated tablet exhibited a lag time followed by burst release, in which outer shell ruptured into two halves. The effect of the core, the polymer characteristics and quantity at the top cover layer, on the lag time and drug release was investigated. The prepared tablets were evaluated for uniformity of weight, hardness, friability, wetting time, in-vitro disintegration time, stability study and drug release study. Fourier transform infrared spectroscopy study showed compatibility between Meloxicam and coating material.
\end{abstract}

Keywords: Pulsatile Release Tablet, Press-coated tablet, Rheumatoid arthritis.

\section{INTRODUCTION}

Oral controlled release drug delivery systems offer a number of advantages over the conventional immediate release delivery preparations. These systems are designed to deliver the drugs at a controlled and predetermined rate thus maintaining their therapeutically effective concentration in systemic circulation for prolonged period. On the other hand, for certain therapies a pulsatile drug release pattern, where the drug is released after welldefined lag time, exhibits significant advantages. It is well documented that most of the body functions display circadian rhythms, e.g. heart rate, stroke volume, blood pressure, blood flow, body temperature, gastric-pH. ${ }^{1}$ Moreover, in a number of organs their functions vary with the time of the day. It is increasingly recognized that there are rhythmic and temporal patterns in the manifestation of many disease states. The symptoms for a number of diseases, such as bronchial asthma, myocardial infarction, angina pectoris, hypertension, rheumatic diseases etc. follow a circadian rhythm. ${ }^{2}$

Circadian rhythms are self-sustaining, endogenous oscillations that occur with a periodicity of about 24 Hours. ${ }^{3}$ Interestingly, the term circadian is derived from the Latin circa which means "about" and dies which can be defined as "a day". Normally, circadian rhythms are synchronized according to internal biologic clocks related to the sleep-wake cycle. Our circadian rhythm is based on sleep-activity cycle and is influenced by our genetic makeup and thereby affects our body's function throughout day and night (24-hour period). Circadian rhythm regulates many body functions in humans like metabolism, physiology, behaviour, sleep pattern, hormone production $^{4}$ as many conditions show circadian pattern, advantage could be taken by timing and adjusting the administration of drugs according to the circadian rhythm of the disease.

Oral pulsatile administration could be useful for the treatment of certain diseases, such as asthma, gastric ulcer, hypertension, ischemic heart disease, arthritis, etc., which exhibit circadian rhythms. A pulsatile release profile is characterized by a lag time followed by rapid and complete drug release. Most pulsatile systems are reservoir systems and usually covered with a barrier. This barrier can be dissolved, eroded or removed at a predetermined period of time after which the drug is dissolved and rapidly released.

Meloxicam is an nonsteroidal anti-inflammatory drug (NSAID) with analgesic and antipyretic properties. Prostaglandins are substances that contribute to inflammation of joints. Meloxicam inhibits prostaglandin synthetase (cylooxygenase 1 and 2) and leads to a decrease of the synthesis of prostaglandins, therefore, inflammation is reduced. ${ }^{5}$ Pulsatile drug delivery system is a controlled drug delivery system where drug is released after a preprogrammed lag time. Various approaches have been used to design a pulsatile release formulation, erodible devices provided with hydrophilic polymer coating are widely used and such a system when exposed to dissolution medium undergo swelling, dissolution and/or erosion. Lag time in such a system can be controlled by using various hydrophilic polymers such as HPMC, polyethylene oxide, sodium alginate, sodium CMC. The concentration and viscosity of these polymers play a significant role in controlling the lag time and release pattern. ${ }^{6}$

A Capsular system in which the body part coated with impermeable polymer and hydrophilic matrix plug sealing the drug formulation is used to prepare pulsatile drug delivery system. Upon contact with aqueous fluids a rapid dissolution would occur and plug undergoes a gradual swelling and finally expluded from the body thus allowing the drug to release. The lag time in such formulation controlled by the time needed for the plug removal and its duration depends on the physical, chemical nature, size and position of the plug. ${ }^{7}$ 
The aim of the present work is to develop a simple one pulse drug delivery system based on dry coated tablet preparation. The system consist of a core tablet containing the drug, an impermeable outer shell and top cover layer barrier that dissolves at predetermined time. Ethyl cellulose is used as insoluble material and a Polyethylene oxide 301, Polyethylene oxide 303 and Hydroxy propyl cellulose used as hydrophilic top layer. The drug is released after removal of top layer of hydrophilic polymers and the lag time being adjusted by properties of the material in top cover, Meloxicam is used as model drug.

\section{MATERIALS AND METHOD}

\section{Materials:}

Meloxicam were obtained from Jai Radhe Sales Ahmedabad, India. Ethyl cellulose, L-Hydroxy propyl cellulose, Polyethylene oxides were gifted from Colorcon Asia Pvt.Ltd. Micro Crystalline Cellulose Croscarmellose Sodium, Magnesium Stearate, Potassium Dihydrogn
Phosphate, Disodium Hydrogen Phosphate was obtained from Loba Cheim Pvt. Ltd. All the other chemicals and reagents were either analytical or pharmaceutical grades.

\section{Tablet Manufacturing Method}

Formulation of Core Tablet by Direct Compression Method:

The rapid release core tablets were prepared using a compression machines (Labpress) with suitable flat punches. The core was made of the suitable mixture of powder blends of Meloxicam, Microcrystalline Cellulose (MCC, Avicel PH-102), Croscarmellose Sodium (Ac-DiSol), Sodium starch glycolate and Magnesium stearate was used in different batches. All above ingredients were dry blended for 20 minutes followed by addition of Magnesium Stearate. The mixture was then further blended for 10 minutes. The $80 \mathrm{mg}$ of the resultant mixture then directly compressed at a pressure of 1 ton for 1 minute using $6 \mathrm{~mm}$ punch and die. Shown in Table no.1

\section{Table No1:- Composition of Core Tablet}

\begin{tabular}{|c|c|c|c|c|c|}
\hline Formulation Code & $\begin{array}{c}\text { Drug } \\
(\mathbf{m g})\end{array}$ & $\begin{array}{c}\text { Microcrystalline } \\
\text { Cellulose (mg) }\end{array}$ & $\begin{array}{c}\text { Cross Carmellose } \\
\text { Sodium (mg) }\end{array}$ & $\begin{array}{c}\text { Magnesium } \\
\text { Stearate (mg) }\end{array}$ & Total (mg) \\
\hline A1 & 15 & 62 & 1 & 2 & 80 \\
\hline A2 & 15 & 61 & 2 & 2 & 80 \\
\hline A3 & 15 & 59 & 4 & 2 & 80 \\
\hline A4 & 15 & 57 & 8 & 2 & 80 \\
\hline A5 & 15 & 55 & & 2 & 80 \\
\hline
\end{tabular}

\section{Formulation of Press Coated Tablet by Direct Mixing:}

In this method the coating material mixtures were previously passed through the sieve no. 44 and half quantity of the powder mixture was used for the upper and lower shell. The press coating of tablets was performed using a rotary tablet machine. A half amount of the powder was filled into the die to make a powder bed, in the center of which core tablet was placed manually. Then, the remaining half of the coating material filled in the die, and the contents were compressed under a sufficient compression force, using a suitable punch. Shown in Table no. 2

Table 2: Composition of Press Coated Tablet by Direct Mixing

\begin{tabular}{|c|c|c|c|c|c|c|c|}
\hline \multirow{2}{*}{$\begin{array}{c}\text { Formulation } \\
\text { Code }\end{array}$} & \multirow{2}{*}{$\begin{array}{c}\text { Core Tablet } \\
\text { Wt.(mg) }\end{array}$} & \multicolumn{4}{|c|}{ Coating Material } & \multirow{2}{*}{$\begin{array}{c}\text { Coating } \\
\text { Material Upper } \\
\text { Layer (mg) }\end{array}$} & \multirow{2}{*}{$\begin{array}{c}\text { Coating Materia } \\
\text { Bottom Layer } \\
(\mathbf{m g})\end{array}$} \\
\hline & & EC (mg) & $\begin{array}{c}\text { L-HPC } \\
(\mathrm{mg})\end{array}$ & $\begin{array}{c}\text { Polyox } \\
301 \text { (mg) }\end{array}$ & $\begin{array}{c}\text { Polyox } \\
303(\mathrm{mg})\end{array}$ & & \\
\hline FA1 & 80 & 150 & 150 & - & - & 150 & 150 \\
\hline FA2 & 80 & 200 & 100 & - & - & 150 & 150 \\
\hline FA3 & 80 & 225 & 75 & - & - & 150 & 150 \\
\hline FA4 & 80 & 250 & 50 & - & - & 150 & 150 \\
\hline FB1 & 80 & 250 & - & 50 & - & 150 & 150 \\
\hline FB2 & 80 & 260 & - & 40 & - & 150 & 150 \\
\hline FB3 & 80 & 270 & - & 30 & - & 150 & 150 \\
\hline FB4 & 80 & 280 & - & 20 & - & 150 & 150 \\
\hline FC1 & 80 & 250 & - & - & 50 & 150 & 150 \\
\hline FC2 & 80 & 260 & - & - & 40 & 150 & 150 \\
\hline FC3 & 80 & 270 & - & - & 30 & 150 & 150 \\
\hline FC4 & 80 & 280 & - & - & 20 & 150 & 150 \\
\hline
\end{tabular}

Formulation of Press Coated Tablets by Impermeable Cup Shaped Method:

An impermeable coating cup consisting of ethyl cellulose was applied in the bottom and around the core tablet. The ethyl cellulose powder was filled into a die of $10 \mathrm{~mm}$ diameter and then was gently compacted to make a powder bed with a flat surface. The core tablet was in turn carefully placed in centre of powder bed next the die was filled with the reminder of the coating powder so that 
surrounding surfaces of the core tablet was fully covered. On the top hydrophilic polymer was added and last bed was compressed to produce the desired core-in-cup system. Shown in Table No. 3

Table 3: Composition of Press Coated Tablet by Cup shaped Method

\begin{tabular}{|c|c|c|c|c|c|}
\hline \multirow{2}{*}{$\begin{array}{c}\text { Formulation } \\
\text { Code }\end{array}$} & $\begin{array}{c}\text { Core Tablet } \\
\text { Wt.(mg) }\end{array}$ & Coating Material in Cup Shape & \multicolumn{3}{|c|}{ Coating Material in Upper Layer } \\
\cline { 3 - 6 } & & EC(mg) & $\begin{array}{c}\text { L-HPC } \\
(\mathbf{m g})\end{array}$ & $\begin{array}{c}\text { Polyox } \\
\mathbf{3 0 1}(\mathbf{m g})\end{array}$ & $\begin{array}{c}\text { Poloyx } \\
\mathbf{3 0 3}(\mathbf{m g})\end{array}$ \\
\hline FD1 & 80 & 100 & 75 & - & - \\
\hline FD2 & 80 & 100 & 100 & - & - \\
\hline FD3 & 80 & 100 & 125 & - & - \\
\hline FD4 & 80 & 100 & 150 & - & - \\
\hline FE1 & 80 & 100 & - & 75 & - \\
\hline FE2 & 80 & 100 & - & 100 & - \\
\hline FE3 & 80 & 100 & - & 125 & - \\
\hline FE4 & 80 & 100 & - & 150 & - \\
\hline FF1 & 80 & 100 & - & - & 75 \\
\hline FF2 & 80 & 100 & - & - & 100 \\
\hline FF3 & 80 & 100 & - & - & 125 \\
\hline FF4 & 80 & 100 & - & - & 150 \\
\hline
\end{tabular}

\section{Evaluation of core and press - coated tablet}

\section{Preformulation Study:}

Bulk density, tapped density, hausner's ratio, carr's index and angle of repose was perform for polymeric blends. ${ }^{8}$

\section{Characterization of Core and Press Coated Tablets}

\section{Thickness:}

Thickness of tablets was determined using Vernier caliper. Five tablets from batch were used, and average values were calculated.

\section{Average Weight:}

To determine average weight, each tablet from formulation was weighed using an electronic balance.

\section{Hardness:}

The hardness was tested using Monsanto tester. The force is measured in kilograms $/ \mathrm{cm}^{2}$.

\section{Uniformity of Content:}

The tablet from each batch was powdered individually and a quantity equivalent to $80 \mathrm{mg}$ of Meloxicam was accurately weighed and dissolved in a suitable volume of $6.8 \mathrm{pH}$ phosphate buffer. After making suitable dilutions the final solution was analyzed spectrophotometrically at $\lambda \max$ of drug.

\section{Friability:}

For each formulation, the friability of 6 tablets was determined using the Roche friabilator (Lab Hosp.). ${ }^{9}$ Twenty tablets were initially weighed (Initial $\mathrm{Wt}$ ) and transferred into friabilator. The Friabilator was operated at $25 \mathrm{rpm}$ for 4 minutes or run up to 100 revolutions. The tablets were weighed again (Final $\mathrm{Wt}$ ). The $\%$ friability was then calculated by,

$$
\mathrm{F}=\frac{\text { Initial Weight }- \text { Final Weight }}{\text { Initial weight }} \times 100
$$

\section{Disintegration Test:}

Six core tablets were selected randomly from each batch for the disintegration test. Disintegration test was performed in simulated colonic fluid (SCF) using Veego Disintegration Tester (microprocessor based), and Disintegration time (DT) was measured. ${ }^{10}$

\section{Drug Excipient Interaction:}

Compatibility of the Drug with the excipients is determined by subjecting the physical mixture of the drug and the polymers of the main formulation to infrared absorption spectral analysis (FTIR). Any changes in chemical composition of the drug after combining it with the polymers were investigated with I.R. spectral analysis.

\section{In vitro Drug Release Study of Press Coated Tablets:}

Dissolution studies were carried out using USP Apparatus II (Veego) at a rotation speed of $50 \mathrm{rpm}$ and at $37 \pm 0.5^{\circ} \mathrm{C}$ using $900 \mathrm{~mL}$ of $0.1 \mathrm{~N} \mathrm{HCl}$ for two hours, followed by 900 $\mathrm{mL}$ of $\mathrm{pH} 6.8$ phosphate buffer as the dissolution media. At appropriate time intervals, $1 \mathrm{ml}$ dissolution samples were withdrawn and replaced with $1 \mathrm{ml}$ of fresh solution maintained at the same temperature. Samples were analyzed by ultraviolet visible spectrophotometry (Shimadzu UV-1800, Japan). The amount of Meloxicam dissolved in the dissolution media was then determined from the calibration curve and the cumulative percentage of Meloxicam released was calculated. ${ }^{11}$

\section{Stability Study:}

After determining the drug content, the optimized batches of tablet were monitored up to 1 month at accelerated stability conditions of temperature and relative humidity $\left(40^{\circ} \pm 2^{\circ} \mathrm{C} / 75 \% \pm 5 \% \mathrm{RH}\right)$. Samples were withdrawn after one month and characterized for Appearance, Weight, Thickness, Hardness, drug content, drug release. The choice of appropriate storage condition during accelerated stability study is necessary to predict the long term stability of Meloxicam tablet. The humidity during storage is also extremely important, considering the hygroscopic nature of hydrophilic polymers. 12

\section{RESULT AND DISCUSSION}

Preformulation Study: 
The powder blend indicated good flowability with the angle of repose values ranging from $26^{\circ}$ to $36^{\circ}$ according to fixed funnel method. The results of bulk density, tapped density and compressibility index are shown in Table No.
4. The result of compressibility index was between $16.12 \pm 1.36$ to $20.78 \pm 2.13$, which indicates good to fair flow properties.

Table 4: Precompression Parameters of Core Tablets

\begin{tabular}{|c|c|c|c|c|c|}
\hline Formulation & $\begin{array}{c}\text { Bulk Density } \\
\left(\mathbf{g m} / \mathbf{c m}^{\mathbf{3}}\right)\end{array}$ & $\begin{array}{c}\text { Tapped Density } \\
\left(\mathbf{g m} / \mathbf{c m}^{\mathbf{3}}\right)\end{array}$ & Hausners Ratio & $\begin{array}{c}\text { Compressibility } \\
\text { Index }\end{array}$ & $\begin{array}{c}\text { Angle of } \\
\text { Repose }\left({ }^{\circ}\right)\end{array}$ \\
\hline A1 & $0.509 \pm 0.008$ & $0.622 \pm 0.003$ & $1.22 \pm 0.02$ & $18.16 \pm 1.34$ & $26.07 \pm 0.67$ \\
\hline A2 & $0.482 \pm 0.017$ & $0.588 \pm 0.011$ & $1.21 \pm 0.01$ & $18.02 \pm 2.45$ & $32.41 \pm 0.92$ \\
\hline A3 & $0.484 \pm 0.004$ & $0.611 \pm 0.023$ & $1.26 \pm 0.03$ & $20.78 \pm 2.13$ & $36.98 \pm 0.43$ \\
\hline A4 & $0.479 \pm 0.006$ & $0.603 \pm 0.013$ & $1.25 \pm 0.04$ & $20.56 \pm 1.22$ & $28.53 \pm 1.23$ \\
\hline A5 & $0.494 \pm 0.013$ & $0.589 \pm 0.006$ & $1.19 \pm 0.07$ & $16.12 \pm 1.36$ & $33.16 \pm 0.11$ \\
\hline
\end{tabular}

Post Compression Characterization of Core Tablet:

Post compression characterization of core tablet are performed and all result are found to be within pharmacopeial limit which is shown in Table No. 5

Table 5: Post Compression Characterization of Core Tablet

\begin{tabular}{|c|c|c|c|c|c|c|}
\hline Formulation & $\begin{array}{c}\text { Weight Variation } \\
(\mathbf{m g})\end{array}$ & $\begin{array}{c}\text { Diameter } \\
(\mathbf{m m})\end{array}$ & $\begin{array}{c}\text { Thickness } \\
(\mathbf{m m})\end{array}$ & $\begin{array}{c}\text { Hardness } \\
\left(\mathbf{k g} / \mathbf{c m}^{\mathbf{2}}\right)\end{array}$ & $\begin{array}{c}\text { Friability } \\
(\mathbf{\%})\end{array}$ & $\begin{array}{c}\text { Drug Content } \\
(\mathbf{\%})\end{array}$ \\
\hline A1 & $79.58 \pm 0.35$ & $6.02 \pm 0.007$ & $2.34 \pm 0.005$ & $4.5 \pm 0.50$ & 0.355 & 99.56 \\
\hline A2 & $79.68 \pm 036$ & $6.02 \pm 0.011$ & $2.36 \pm 0.016$ & $4.33 \pm 0.03$ & 0.361 & 98.80 \\
\hline A3 & $79.47 \pm 0.31$ & $6.01 \pm 0.015$ & $2.39 \pm 0.014$ & $4.00 \pm 0.00$ & 0.328 & 98.33 \\
\hline A4 & $79.70 \pm 0.31$ & $6.01 \pm 0.011$ & $2.40 \pm 0.008$ & $4.00 \pm 0.50$ & 0.348 & 98.26 \\
\hline A5 & $79.61 \pm 0.39$ & $6.02 \pm 0.008$ & $2.42 \pm 0.008$ & $3.83 \pm 0.23$ & 0.308 & 98.93 \\
\hline
\end{tabular}

\section{Post Compression Characterization of Press Coated Tablet:}

Post compression Characterization of Press Coated Tablet are performed and all result are found to be within pharmacopeial limit which is shown in Table No. 6

Table 6: Post Compression Characterization of Press Coated Tablet

\begin{tabular}{|c|c|c|c|c|c|c|}
\hline Formulation & $\begin{array}{c}\text { Weight Variation } \\
\text { (mg) }\end{array}$ & $\begin{array}{l}\text { Diameter } \\
(\mathbf{m m})\end{array}$ & $\begin{array}{l}\text { Thickness } \\
\text { (mm) }\end{array}$ & $\begin{array}{l}\text { Hardness } \\
\left(\mathrm{kg} / \mathrm{cm}^{2}\right)\end{array}$ & $\begin{array}{c}\text { Friability } \\
(\%)\end{array}$ & $\begin{array}{c}\text { Drug } \\
\text { Content }(\%)\end{array}$ \\
\hline FA1 & $379.34 \pm 0.26$ & $10.02 \pm 0.003$ & $6.5 \pm 0.12$ & $9.23 \pm 1.30$ & 0.56 & 99.34 \\
\hline FA2 & $379.44 \pm 0.72$ & $10.01 \pm 0.016$ & $6.4 \pm 0.13$ & $9.54 \pm 1.41$ & 0.54 & 98.27 \\
\hline FA3 & $379.93 \pm 0.47$ & $10.00 \pm 0.002$ & $6.5 \pm 0.09$ & $9.40 \pm 2.42$ & 0.63 & 99.23 \\
\hline FA4 & $379.56 \pm 0.07$ & $10.00 \pm 0.023$ & $6.6 \pm 0.21$ & $8.92 \pm 1.32$ & 0.57 & 97.85 \\
\hline FB1 & $379.83 \pm 0.35$ & $10.03 \pm 0.011$ & $6.5 \pm 0.23$ & $9.44 \pm 0.13$ & 0.53 & 98.66 \\
\hline FB2 & $380.21 \pm 036$ & $10.00 \pm 0.045$ & $6.4 \pm 0.15$ & $10.72 \pm 1.11$ & 0.72 & 96.49 \\
\hline FB3 & $379.24 \pm 0.13$ & $10.01 \pm 0.005$ & $6.5 \pm 0.12$ & $8.86 \pm 1.76$ & 0.56 & 97.64 \\
\hline FB4 & $379.50 \pm 0.64$ & $10.00 \pm 0.003$ & $6.5 \pm 0.12$ & $9.32 \pm 1.81$ & 0.52 & 99.83 \\
\hline FC1 & $380.12 \pm 0.75$ & $10.02 \pm 0.009$ & $6.5 \pm 0.13$ & $8.22 \pm 0.45$ & 0.51 & 97.23 \\
\hline FC2 & $379.32 \pm 035$ & $10.02 \pm 0.017$ & $6.4 \pm 0.23$ & $9.64 \pm 1.32$ & 0.73 & 99.68 \\
\hline FC3 & $379.18 \pm 0.08$ & $10.03 \pm 0.002$ & $6.6 \pm 0.14$ & $9.75 \pm 2.75$ & 0.64 & 99.32 \\
\hline $\mathrm{FC} 4$ & $379.40 \pm 0.17$ & $10.01 \pm 0.035$ & $6.5 \pm 0.11$ & $9.63 \pm 1.44$ & 0.63 & 97.69 \\
\hline FD1 & $254.24 \pm 0.91$ & $10.02 \pm 0.015$ & $6.5 \pm 0.12$ & $10.11 \pm 0.13$ & 0.54 & 98.56 \\
\hline FD2 & $279.56 \pm 0.63$ & $10.00 \pm 0.005$ & $6.6 \pm 0.13$ & $9.53 \pm 1.27$ & 0.61 & 99.11 \\
\hline FD3 & $305.04 \pm 0.82$ & $10.00 \pm 0.023$ & $6.4 \pm 0.11$ & $9.32 \pm 2.14$ & 0.56 & 99.45 \\
\hline FD4 & $329.44 \pm 0.43$ & $10.01 \pm 0.007$ & $6.6 \pm 0.14$ & $9.06 \pm 1.13$ & 0.67 & 97.48 \\
\hline FE1 & $254.32 \pm 0.34$ & $10.01 \pm 0.034$ & $6.4 \pm 0.12$ & $8.52 \pm 1.41$ & 0.57 & 96.89 \\
\hline FE2 & $279.78 \pm 0.16$ & $10.00 \pm 0.012$ & $6.5 \pm 0.13$ & $9.12 \pm 1.09$ & 0.64 & 98.34 \\
\hline FE3 & $304.43 \pm 0.12$ & $10.00 \pm 0.113$ & $6.5 \pm 0.07$ & $8.89 \pm 2.41$ & 0.55 & 97.84 \\
\hline FE4 & $329.70 \pm 0.27$ & $10.00 \pm 0.005$ & $6.5 \pm 0.23$ & $9.76 \pm 1.14$ & 0.73 & 98.92 \\
\hline FF1 & $254.27 \pm 0.72$ & $10.03 \pm 0.012$ & $6.6 \pm 0.12$ & $9.64 \pm 1.33$ & 0.68 & 99.51 \\
\hline $\mathrm{FF} 2$ & $279.92 \pm 0.68$ & $10.02 \pm 0.003$ & $6.5 \pm 0.12$ & $10.04 \pm 1.25$ & 0.66 & 97.39 \\
\hline FF3 & $304.33 \pm 0.32$ & $10.02 \pm 0.112$ & $6.4 \pm 0.14$ & $9.33 \pm 1.28$ & 0.55 & 99.21 \\
\hline FF4 & $329.58 \pm 0.21$ & $10.00 \pm 0.005$ & $6.5 \pm 0.13$ & $9.78 \pm 1.45$ & 0.54 & 99.23 \\
\hline
\end{tabular}




\section{Disintegration Test:}

The core tablets were found to have disintegration time in following order A1 $<$ A $2<\mathrm{A} 3<\mathrm{A} 4<\mathrm{A} 5$ Thus, it was found that formulation A5 shows least disintegration time of about 76 seconds. Tablets A5 It contains Cross Carmellose Sodium in concentration of $8 \%$ hence it was selected for further study. All data related to disintegration are shown Figure No. 1

\section{Drug Excipient Interaction:}

FT-IR spectra of Meloxicam (A), Physical mixture (Meloxicam+HPC) (B), Meloxicam+Polyox 301(C), Meloxicam+Polyox 303(D), Meloxicam+Ethyl Cellulose (E), Optimised formulation (F) was shown in Figure No. 2. The characteristic absorption peaks of Meloxicam was found at 3290 and $1622 \mathrm{~cm}-1$ (N-H stretching), $1552 \mathrm{~cm}-1$ (C-O stretching), 1163 ( $\mathrm{S}=\mathrm{O}$ stretching) and $1640 \mathrm{~cm}-1$ $(\mathrm{C}=\mathrm{N}$ stretching). The spectra revealed no difference in positions of the absorption bands, especially with respect to $\mathrm{OH}, \mathrm{NH}$ hence providing the evidence for the absence of hydrogen bonding interaction in between polymers and Meloxicam. As shown in Figure No. 2

\section{disintegration test}

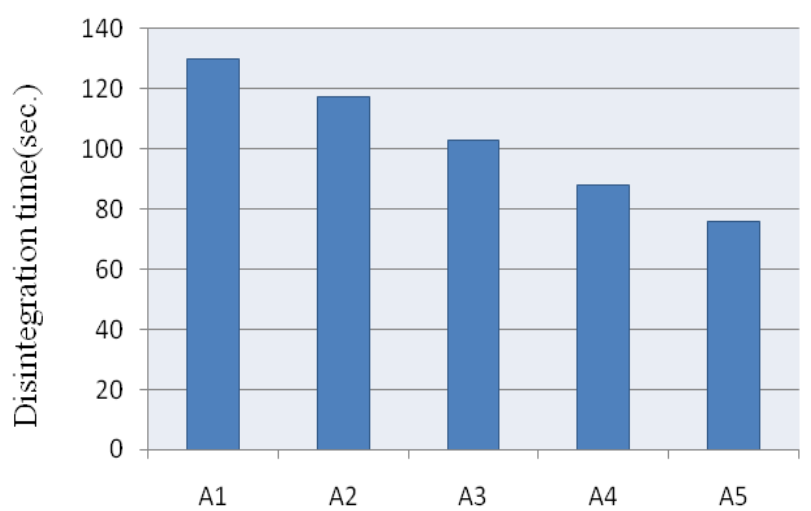

Figure 1: Disintegration time of Core tablets

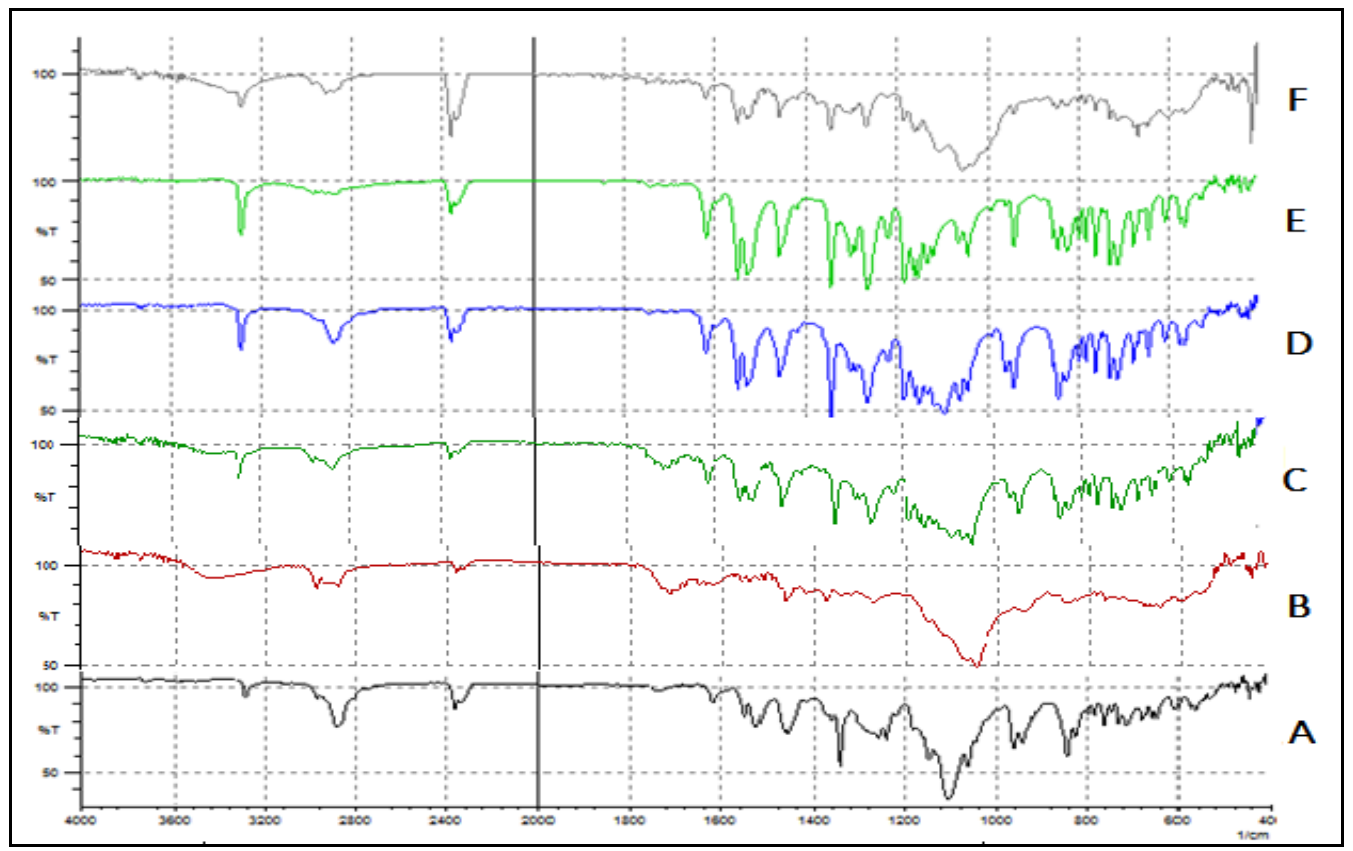

Figure 2: IR spectrum of Meloxicam (A), Meloxicam+HPC (B), Meloxicam+Polyox 301(C), Meloxicam+Polyox 303(D), Meloxicam+Ethyl cellulose (E), Optimised formulation (F).

\section{In Vitro Drug Release Study of Core Tablets:}

The core tablet formulation (A5) containing highest amount of Cross Carmellose Sodium showed fast disintegration. Shown in Figure No.3

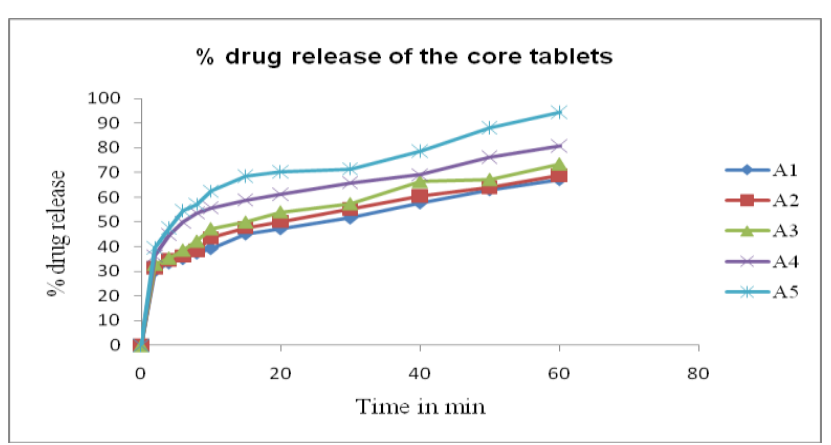

Figure 3: Dissolution profile of core tablet (A1-A5)
In Vitro Drug Release Study of Press - Coated Tablets:

In formulation FA1-FA4, FB1-FB4, FC1-FC4 it showed that lag time decreases with increasing concentration of hydrophilic polymer L-HPC, Polyox 301, Polyox 303. Dissolution media get penetrate into coating layer slowly and it solubilises L-HPC. In contact with dissolution media Polyox 301 erodes easily so the ethyl cellulose gets free from mixture and the core tablet get exposed to dissolution media. In contact with dissolution media Polyox303 get swelled and due to pressure developed it distract ethyl cellulose. Hence drug diffuses rather than bursting of tablet. Batch FA4, FB4, FC4 showed highest lag time because it contains high concentration of ethyl cellulose and low concentration of L-HPC, Polyox 301, Polyox 303. All data are shown in Figure No. 4, 5 and 6. 


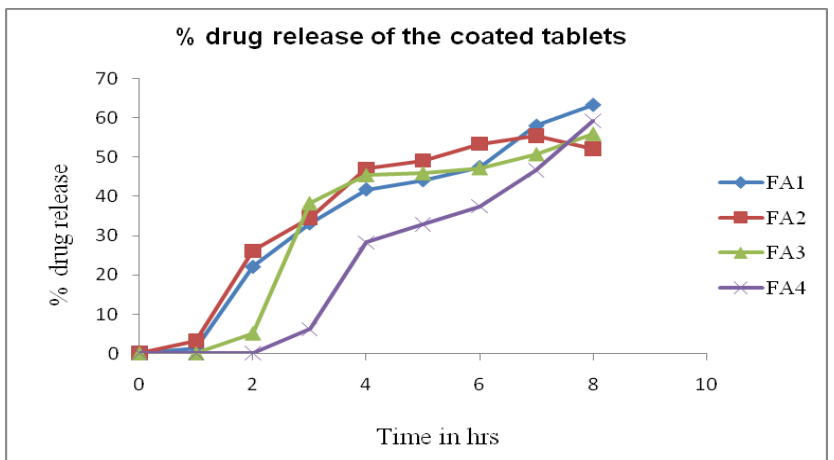

Figure 4: Dissolution profile of Batch FA1-FA4

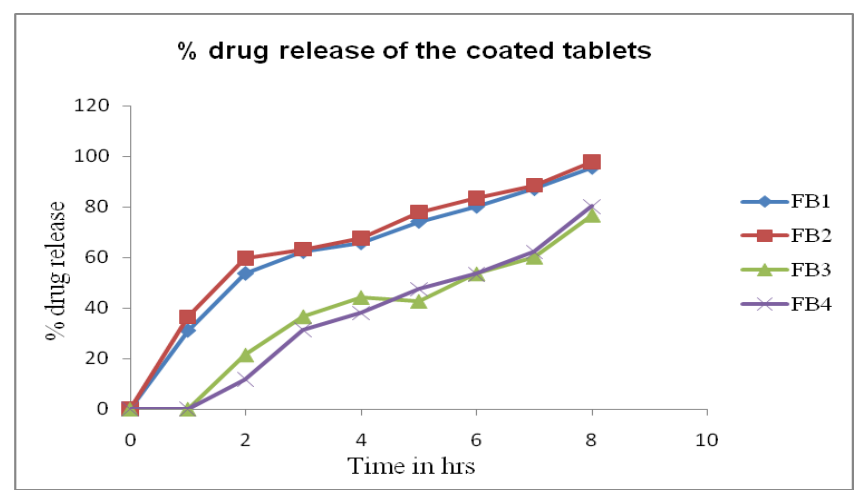

Figure 5: Dissolution profile of Batch FB1-FB4

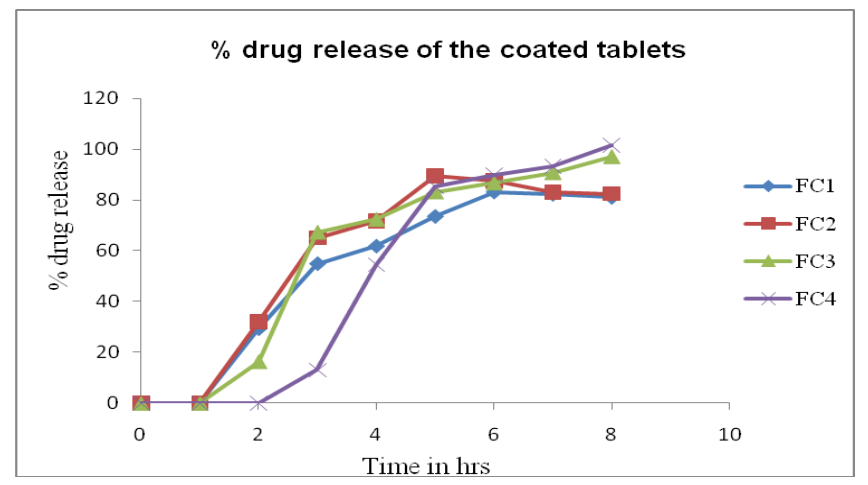

Figure 6: Dissolution profile of Batch FC1-FC4

In contacts with dissolution media L-HPC, Polyox 301, Polyox 303 gets eroded slowly. This cause's dissolution media to enter into core tablet resulting in bursting of tablet due to pressure develop by superdisintegrant. It showed that lag time increases with increasing concentration L-HPC, Polyox 301, Polyox 303. Hence we can said that lag time is directly proportional to the thickness of top layer. All data are shown in Figure No. 7,8 and 9 .

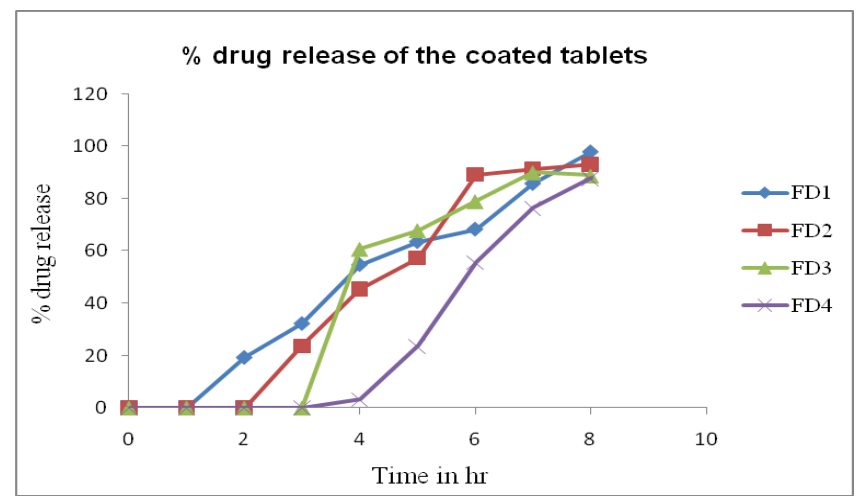

Figure 7: Dissolution profile of Batch FD1-FD4 C 2011, JDDT. All Rights Reserved

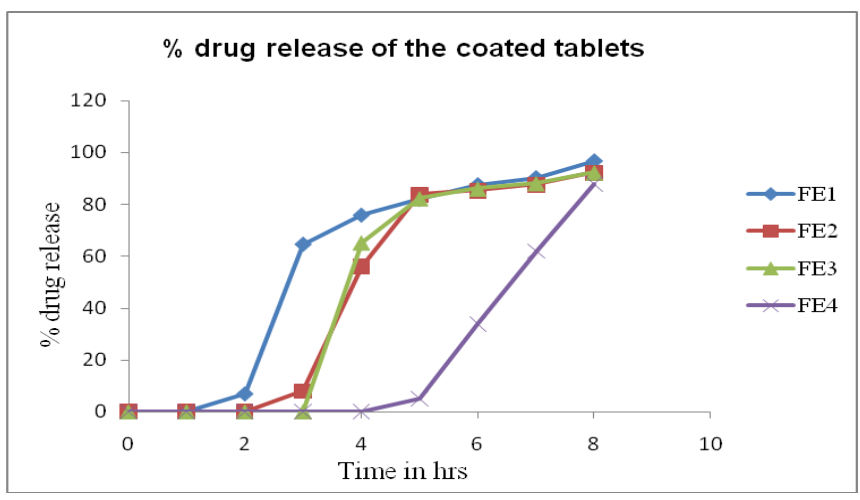

Figure 8: Dissolution profile of Batch FE1-FE4

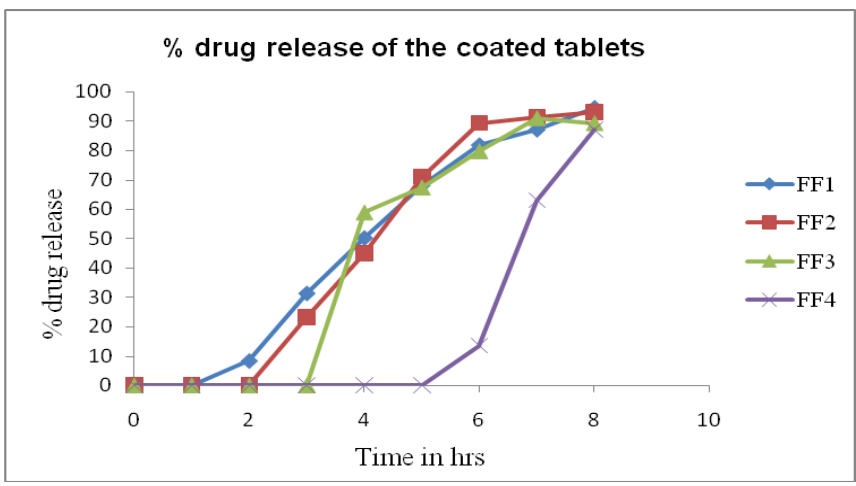

Figure 9: Dissolution profile of Batch FF1-FF4

After observation it was found that Batch FA4 showed sustain type of drug release which is not requiring in Pulsatile tablet. This shows that drug release through diffusion mechanism as tablet not give essential lag time. Batch FB4 and FC4 follows lag time of $3 \mathrm{Hr}$. but fail to give rapid release after that. Hence direct mixing may be unsatisfactory method for tested polymer combinations. As shown in Figure No.10

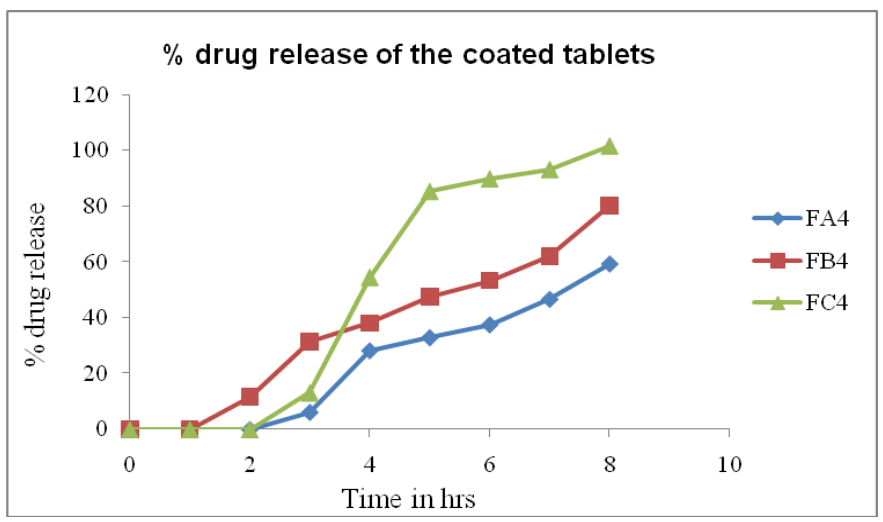

Figure 10: Dissolution profile of comparison between FA4, FB4, and FC4

In Batch FD4 ethyl cellulose as impermeable cup and L$\mathrm{HPC}$ as top layer. It showed bursting effect at $5 \mathrm{hr}$. But batch FE4 and FF4 showed bursting effect at $6 \mathrm{Hrs}$. Batch FE4 contain hydrophilic polymer Polyox 301. Polyox 301 is low molecular weight and erodible nature. Due to it gets eroded slowly in contacts with dissolution media and after lag period of time upper Polyox 301 gets removed completely and released drug. Batch FF4 showed slow release because it contain high molecular weight polymer polyox 303 which gets swelled in contacts with dissolution media and releases drug after lag period of time $6 \mathrm{Hrs}$. Shown in Figure No.11 


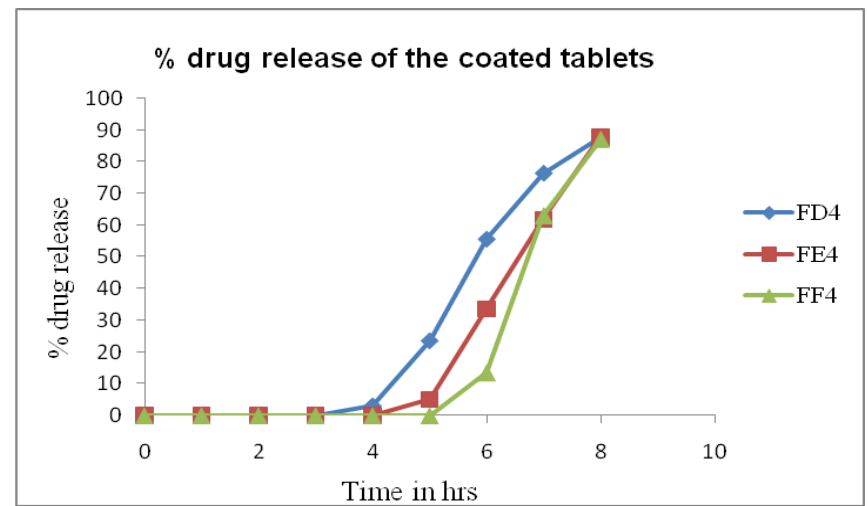

Figure 11: Dissolution profile of comparison between D4, E4, and F4

It was found that direct mixing methods may permeate dissolution media from all sides of tablets because of presence of hydrophilic polymer it diffuses drug from all sides but in impermeable cup shaped method dissolution media do not enter from all sides because presence of hydrophobic polymer it can enter into only one side that is top layer which is hydrophilic. This gets eroded slowly and exposes tablet. Hence in impermeable method thickness of top layer is directly proportional to lag time of tablet. Shown in Figure No.12

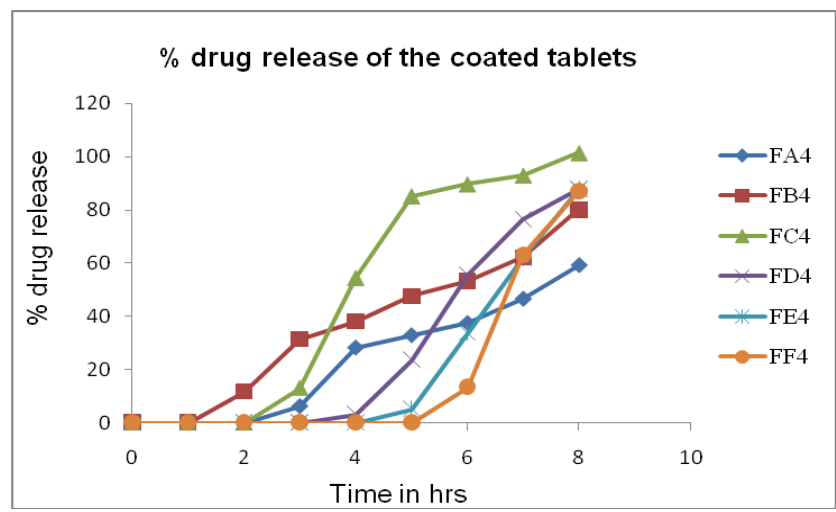

Figure 12: Dissolution profile of Comparison between all best batches from direct mixing and impermeable cup shaped method

\section{Stability study:}

The stability study of the FF4 batch in which the tablets were monitored. There was little bit but no large difference was observed in the evaluation of the FF4 batch. The dissolution study of the optimized batch at zero month and one month show no changes in drug release profile both the dissolution study show the typical pulsatile profile. All data of Stability study Shown in Table No.7 and Figure No 13

Table 7: Stability Study

\begin{tabular}{|c|c|c|}
\hline Parameter & At Temp. $40^{\circ} \pm 20 \mathrm{C}$ & RH $75 \% \pm 5 \%$ \\
\hline Appreance & Off white & Off white \\
\hline Drug Content (\%) & $99.23 \pm 0.51$ & $97.56 \pm 0.69$ \\
\hline Drug Release after Lag time. (\%) & 87.16 & 85.93 \\
\hline
\end{tabular}

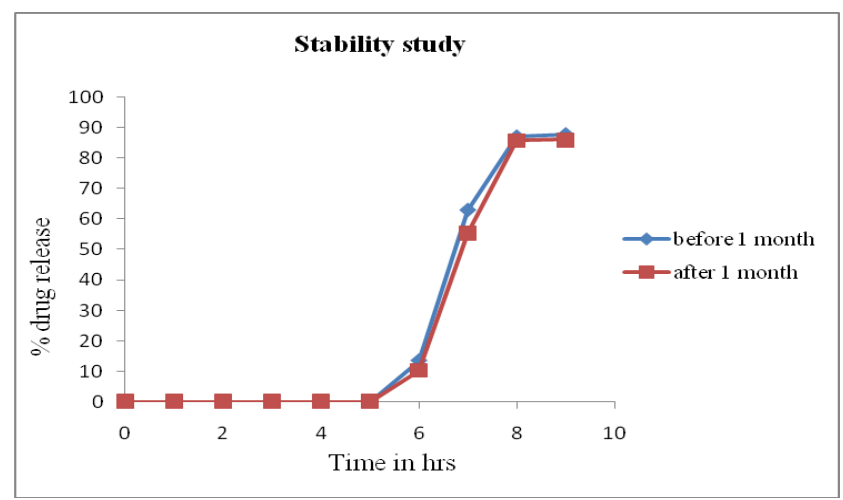

Figure 13: \% drug release before and after stability Study

\section{CONCLUSION}

Results of present work demonstrated that combination of both hydrophilic and hydrophobic polymers by impermeable cup shaped method could be successfully employed for formulating pulsatile release tablets of Meloxicam. The FF4 formulation combination of Ethyl Cellulose (bottom cup) and Polyox 303 (top layer) was capable of extending the drug release after 6 hours.

\section{ACKNOWLEDGMENT}

The authors are greatful to Dr. M. J. Patil, Principal Marathwada Mitra Mandal's college of pharmacy, Pune for his constant support and encouragement. 


\section{REFERENCES}

1. Devdhawala MG, Seth AK. Current status of chronotherapeutic drug delivery system: An overview. J. Chem. Pharm. Res., 2010, 2(3), 312-328

2. Smolensky MH, Peppas NA. Chronobiology, Drug Delivery, and Chronotherapeutics. Adv Drug Deli Rev 2007, 59, 828-851.

3. Jha N, Bapat S. Chronobiology and chronotherapeutics. Kathmandu University Medical Journal. 2004, 2(8), 384-388.

4. Arora S, Ali J, Ahuja A, Baboota S, Qureshi J. Pulsatile drug delivery systems: An approach for controlled drug delivery. Indian J. Pharm. Sci., 2006, 68(3), 295-300.

5. http://www.drugbank.ca/search

6. Efenkatis M, Koligliati S, Vlachou M, Design and evaluation of a dry coated drug delivery system, an impermeable cup, swellable top layer and pulsatile release. International journal of Pharmaceutics. 2006, 311, 147-156, 14

7. Mastiholomath VS, Dandagi PM, International journal of pharmaceutic, 2007, 328, 49-56,
8. Borgaonkar PA, Bushetti SS, Najmuddin M, Formulation and Evaluation of Pulsatile Drug Delivery System of Metoprolol Tartarate Using Core in Cup Tablet, American Journal of Medicine and Medical Sciences 2012, 2(6), 114-122

9. Rane AB, Gattani SG, Kadam VD, and Tekade AR, Formulation and Evaluation of Press Coated Tablets for Pulsatile Drug Delivery Using Hydrophilic and Hydrophobic Polymers, Chem. Pharm. Bull 2009, 57(11), 1213-1217

10. Lachman L, Liberman HA, Kanig JL, Banker GS, Anderson NR. The Theory and Practice of Industrial Pharmacy, 3rd edition Mumbai: Vanghese publishing house; 2003. 293-345.

11. Moon A, Kondawar M, Shah R. Formulation and evaluation of press -coated indomethacin tablets for pulsatile drug delivery system, Journal of Pharmacy Research, 2011, 4(3), 564-566.

12. Jagdale S, Sali M, Barhate A, Loharkar J, Kuchekar B, Chabukswar A, Development of pulsatile release tablets of Atenolol with swelling and rupturable layers. Int J Appl Pharma, 2010, Vol 2, Issue 3, 31- 40 